\title{
Ocular blood flow levels and visual prognosis in a patient with nonischemic type central retinal vein occlusion
}

This article was published in the following Dove Press journal:

Clinical Ophthalmology

3। August 2009

Number of times this article has been viewed

\author{
Kimihito Maeda \\ Futoshi Ishikawa \\ Hiroshi Ohguro \\ Department of Ophthalmology, \\ Sapporo Medical University, \\ School of Medicine, Sapporo, Japan
}

Correspondence: Hiroshi Ohguro Department of Ophthalmology, Sapporo Medical University School of Medicine, South-I, West-16, Chuo-ku, Sapporo, Japan 060-8543

Tel +8 I II 6II 2 I I I (Ext. 3435)

Fax +8I II 6136575

Email ooguro@sapmed.ac.jp

\begin{abstract}
We look at the case of a 39-year-old female patient suffering from a sudden decrease in her left visual acuity (0.08). Her macular edema was examined using optical coherence tomography, and her optic disc blood flow was examined with laser speckle flowgraphy (LSFG). Additionally, the degree of seriousness of the central vein occlusion was evaluated through fluorescein angiography (FA). Ocular fundus findings revealed central vein occlusion associated with macular edema, and FA determined her disease type as a nonischemic-central vein occlusion. Daily doses of $100 \mathrm{mg}$ of aspirin were administered orally to the patient. Upon administration, her ocular blood flow almost immediately increased. In this study, we demonstrate the potential of LSFG as a means to investigate ocular blood flow.
\end{abstract}

Keywords: ocular blood flow, nonischemic central retinal vein occlusion, laser speckle flowgraphy

\section{Introduction}

Laser speckle flowgraphy (LSFG) can noninvasively measure both major and minute vessels of the retinal blood flow in real time. ${ }^{1}$ This method can visualize retinal blood flow by using laser dispersion. ${ }^{2}$ The obtained data indicate a relative value of retinal blood flow levels and therefore can easily be compared consecutively. ${ }^{2}$ As far as we can ascertain, to date no study is available that describes the effects of internal medicines toward optic nerve head $(\mathrm{ONH})$ blood flow levels in patients with retinal vein occlusion, although several drugs, including anticoagulants, are frequently used in our clinic. We report herewith a unique case of (nonischemic) central retinal vein occlusion (NI-CRVO) associated with macular edema successfully treated by oral aspirin administration. The case caused significant improvement of the $\mathrm{ONH}$ blood flow levels through LSFG and retinal hemodynamics through fluorescein angiography (FA).

\section{Case report}

A 39-year-old woman noticed a sudden decrease in her left visual acuity and was referred to our hospital two days later. Her decimal visual acuity was 1.2/OD and 0.08/OS. Ocular fundus findings included massive dilatation of the retinal veins, widespread dot-blot hemorrhages, and multiple cotton-wool spots (Figure 1A). In addition, macular edema was determined by optical coherence tomography (Zeiss Straus OCT; OCT3, Carl Zeiss Meditec, Jena, Germany) (Figure 1E). 


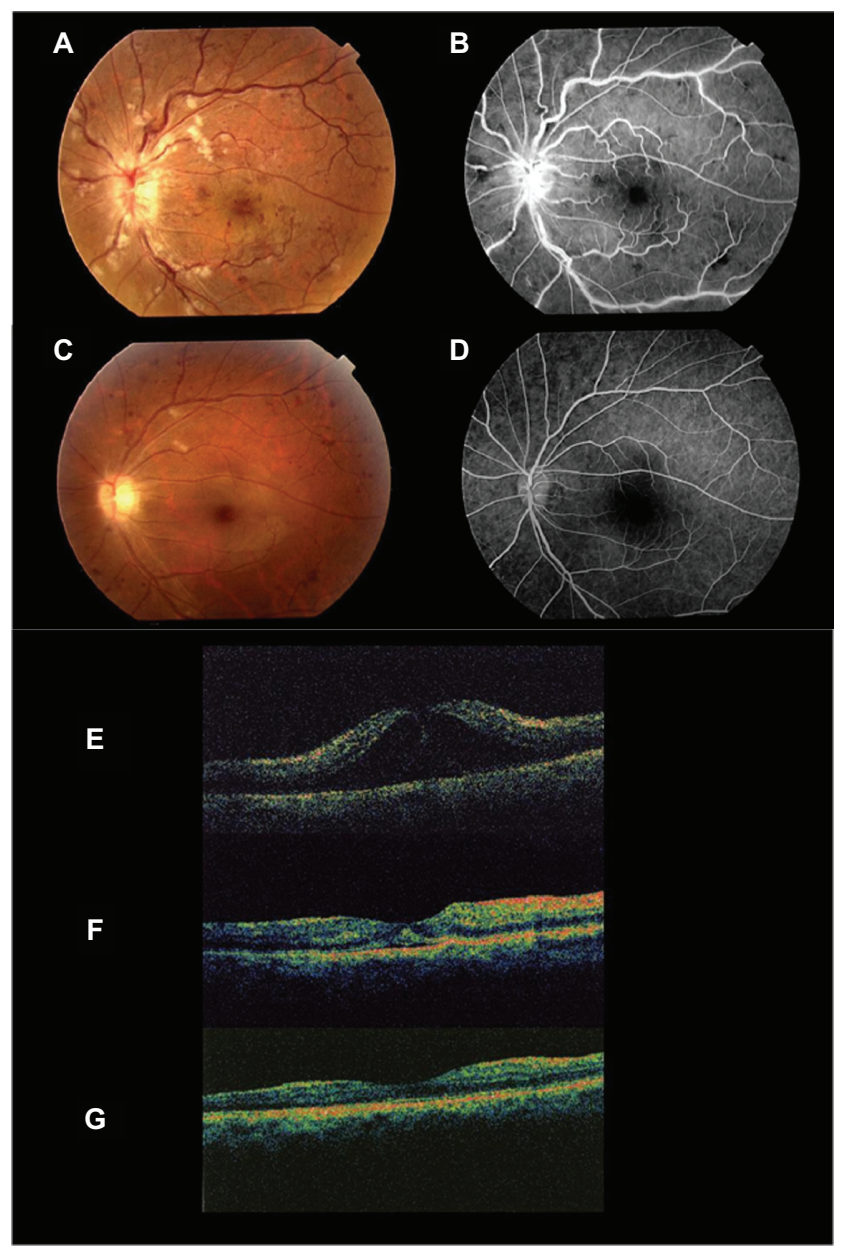

Figure I The fluorescein angiography photograph (B) shows a fluorescence block for multiple dot subretinal hemorrhage, cotton-wool spots and vein meandering with the color fundus photograph (A), but it does not show the avascular area. Three months later, the fundus photograph $(\mathbf{C})$ shows an almost normal retina appearance although dot subretinal hemorrhage and cotton-wool spots remain. The flourescein angiography photograph (D) shows no abnormality. The OCT shows remarkable macular edema, with the macular thickness indicated at $638 \mu \mathrm{m}$ (E). (F) Macular thickness the following day shows $220 \mu \mathrm{m}$. The retinal thickness was reduced to $140 \mu \mathrm{m}$ three months later.

Abbreviation: OCT, optical coherence tomography.

Based on these findings, and because FA showed no presence of nonischemic lesions, she was diagnosed as having nonischemic central retinal vein occlusion (NI-CRVO) associated with macular edema. LSFG indicated $\mathrm{ONH}$ blood flow levels were markedly decreased (Figure 2A). No systemic diseases, including hypertension, were detected. Oral aspirin treatment was then administered to the patient $(100 \mathrm{mg} /$ day $)$. The macular edema and the ONH circulation, particularly the central retinal artery (CRA) blood flow, improved a few days after the aspirin administration was initiated (Figures $1 \mathrm{E}$ and F, Figures 2A and $\mathrm{C}$ ), and her left visual acuity also improved to 0.8 . Three months later, her visual acuity was restored to 1.2 , and macular edema had disappeared completely (Figure 1G).
In terms of ocular hemodynamics, LSFG showed a further increase of CRA blood flow and no abnormal findings by FA (Figure 2D and E).

\section{Discussion}

Retinal vein occlusion (RVO) is the second most common retinal vascular disease after diabetic retinopathy, affecting not only the elderly, but also young patients. ${ }^{3}$ NI-CRVO is a disorder associated with macular edema and can heal spontaneously, but the time period in which macular edema heals is unknown. In NI-CRVO, retinal vein thrombosis or unidentified immunity-related vasculitis causes increased venous pressure and, as a result, may lead to retinal capillary decompensation with macular edema. ${ }^{4}$ We investigated this by utilizing PubMed internet research concerning the connection between the increment of the central retinal artery flow and rapid recovery from macular edema. Unfortunately, we could not find pertinent information on this matter. The pathogen of the CRVO in young people suggested a systemic disorder or arteriovenous communications of the retina. ${ }^{3}$ However we did not find any systemic disorders or retinal vessels abnormalities in the patient. Her retinal symptoms showed remarkable improvement after oral aspirin administration. We considered the possibility that thrombotic release of the central retinal vein was accompanied with CRA blood flow improvement based on reports that CRVO is caused by CRA thrombosis. ${ }^{5}$ Due to the fact that CRA blood flow change was rapid, LSFG seems to be an optimal method to measure the short-term hemodynamics. As for the examination for FA, an evaluation of the vasa sanguinea retinae hemodynamics is possible, but quantifying retinal blood flow improvement is difficult unless a special device is utilized. ${ }^{6}$ Moreover, FA is invasive and repeated experimentation over a short period is difficult. In the present report, a significant increase in the ONH blood flow levels due to an increase of LSFG was recognized upon oral administration of aspirin, and this correlated with macular edema reduction by OCT and visual acuity improvement. It is unknown whether macular edema and central retinal artery blood flow were improved by aspirin administration or by natural causes, but implication of LSFG evaluation of the hemodynamics of the ONH circulation may be a promising tool for monitoring the progression of retinal vascular diseases.

\section{Disclosures}

The authors report no conflicts of interest in this work. 


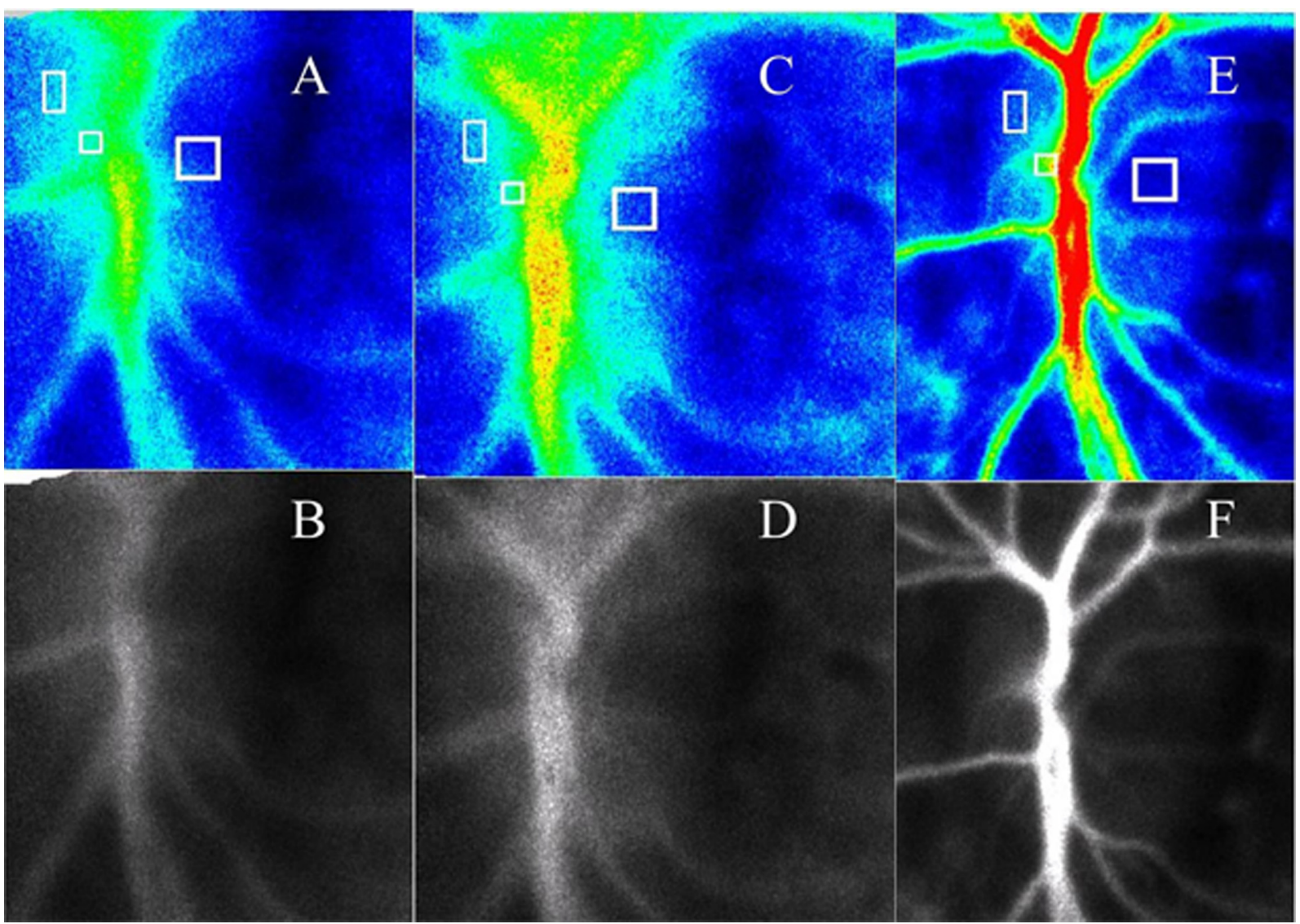

Figure 2 Optic nerve head blood flow levels by LSFG. We show examinations with LSFG from the first and second days, as well as three months later. B, D, and $\mathbf{F}$ are monochrome-converted images of $\mathbf{A}, \mathbf{C}$ and $\mathbf{E}$, respectively, which makes observing optic nerve heads and vessels easier. The square shows the blood flow (A, C, E) measurement part of CRA, both the optic nerve head of the nasal side as well as the temporal side. The blood flow rate in the CRA improved by $84.3 \%$, on the temporal side it improved by $32 \%$ and that of the nasal side showed a $3.9 \%$ improvement. Three months later, the CRA blood flow rate was shown to have improved by $253 \%$, although that of the temporal side and nasal side of $\mathrm{ONH}$ decreased by $10 \%$ and $15 \%$, respectively.

Abbreviations: CRA, central retinal artery; LSFG, laser speckle flowgraphy; ONH, optic nerve head.

\section{References}

1. Goro W, Hitoshi F, Shoji K. Imaging of choroidal hemodynamics in eyes with polypoidal choroidal vasculopathy using laser speckle phenomenon. Jpn J Ophthalmol. 2008;52:175-181.

2. Yasuhiro T, Makoto A, Ken T, Miyuki N, Atsuo T, Hitoshi F. Real-time measurement of human optic nerve head and choroid circulation, using the laser speckle phenomenon. Jpn J Ophthalmol. 1997;41:49-54.

3. Giuffré G, Randazzo-Papa G, Palumbo C. Central retinal vein occlusion in young people. Documenta Ophthalmologica. 1992;80:127-132.
4. Verougstraete C, Demol S. Macular edema in retinal vein occlusion. Bull Soc Belge Ophthalmol. 1991;240:35-47.

5. Holmin N, Ploman KG. Thrombosis of central vein of retina treated with heparin. Lancet. 1938;1:664.

6. Hickam JB, Frayser R. A photographic method for measuring the mean retinal circulation time using fluorescein. Invest Ophthalmol. 1965;4:876-884.
Clinical Ophthalmology

\section{Publish your work in this journal}

Clinical Ophthalmology is an international, peer-reviewed journal covering all subspecialties within ophthalmology. Key topics include: Optometry; Visual science; Pharmacology and drug therapy in eye diseases; Basic Sciences; Primary and Secondary eye care; Patien Safety and Quality of Care Improvements. This journal is indexed on

\section{Dovepress}

PubMed Central and CAS, and is the official journal of The Society of Clinical Ophthalmology (SCO). The manuscript management system is completely online and includes a very quick and fair peer-review system, which is all easy to use. Visit http://www.dovepress.com/ testimonials.php to read real quotes from published authors. 